\title{
DINÂMICA DO USO E COBERTURA DA TERRA NO CAMPUS DA UNIVERSIDADE FEDERAL DE LAVRAS DE 1964 A 2009
}

\author{
Elizabeth Ferreira ${ }^{1}$, Antonio Augusto Aguilar Dantas ${ }^{2}$, Alcione de Oliveira ${ }^{3}$, Rodrigo Villela Machado ${ }^{4}$
}

(recebido: 28 de outubro de 2010; aceito: 28 de setembro de 2012)

RESUMO: Neste trabalho, objetivou-se identificar, quantificar e analisar as mudanças ocorridas no campus da Universidade Federal de Lavras, município de Lavras, MG. Imagens do ano de 2009 do satélite QUICKBIRD e fotografias aéreas verticais dos anos de 1985, 1979, 1971 e 1964 foram usadas para produzir uma série de cartas de uso e cobertura da terra. O trabalho teve início com a ortorretificação da imagem de satélite QUICKBIRD e das fotografias aéreas. A identificação e a definição das classes de uso e cobertura da terra foram obtidas a partir de levantamentos de campo em 2009. A partir dessas informações, foram então construídos os mapas de uso e cobertura da terra. Por fim, foram feitas a quantificação e a análise das mudanças ocorridas no período estudado. Os resultados mostraram que: em 1964 a "área urbanizada" do campus que somava 6,24 ha, aumentou para 65,79 ha em 2009 e que o aumento mais expressivo dessa classe ocorreu entre os anos de 1964 (6,24 ha) e 1971 (24,4 ha). O menor valor de área de "vegetação natural" encontrado no campus foi de 38,38 ha em 1971, sendo que, a partir de 1979, essa situação foi alterada e em 2009 o campus apresentou 113,18 ha dessa categoria. Em relação à classe "água", observou-se que antes de 1971 não existia nenhuma represa no campus. A maior parte do campus, antes utilizada para "atividades agrícolas", teve uma redução significativa dessa categoria, de 384,19 ha em1964, para 271,16 ha em 2009.

Palavras-chave: Sensoriamento remoto, análise temporal, SIG.

\section{LAND USE AND LAND COVER DYNAMICS ON THE CAMPUS OF FEDERAL UNIVERSITY OF LAVRAS FROM 1964 TO 2009}

\begin{abstract}
This study identified, quantified and analyzed changes in land use and cover on the campus of Federal University of Lavras campus, located in Lavras city (Minas Gerais State). The 2009 QuickBird satellite imagery and 1985, 1979, 1971, 1964 vertical aerial photographs were used to produce a set of land use and land cover maps. The work started with the orthorectification of the QuickBird satellite imagery and vertical aerial photographs. The identification and definition of land cover and land use classes were obtained from field surveys in 2009. First, the land cover and land use maps were made from that information. Finally, the quantification and analysis of changes were performed at the imagery time range. The results showed that in 2009 the "urbanized area class" of the campus reached 65.79 ha and that the most significant increase of this class occurred between the years $1964(6.24 \mathrm{ha})$ and 1971 (24.4 ha). The smallest area of "forest land class" found on the campus was 38.38 ha in 1971, and from 1979 on this situation has been improved reaching 113.18 ha of "forest land class" in 2009. For the "water class" there was not any dam constructed yet in the campus before 1971. Most of the campus area, previously used for "agricultural land class" had a significant reduction within this category, from 384.19 ha in 1964 to 271.16 ha in 2009.
\end{abstract}

Key words: Remote sensing, temporal analysis, GIS.

\section{INTRODUÇÃO}

As técnicas de sensoriamento remoto, apoiadas no uso de fotografias aéreas verticais convencionais e de imagens de satélite, constituem as principais fontes de dados para a elaboração de mapas de uso e cobertura da terra (ANDERSON et al., 1976; INSTITUTO BRASILEIRO

\section{DE GEOGRAFIA E ESTATÍSTICA - IBGE, 2006; LILLESAND et al., 2008).}

O levantamento sobre o uso e a cobertura da terra comporta análises e mapeamentos que são de grande utilidade para o conhecimento das formas de uso e de ocupação do espaço, constituindo importante ferramenta de planejamento e de orientação à tomada de decisão (IBGE,

\footnotetext{
${ }^{1}$ Engenheira Agrícola, Professora Doutora em Agronomia (Irrigação e Drenagem) - Universidade Federal de Lavras/UFLA - Departamento de Engenharia - Cx. P. 3037 - 37200-000 - Lavras, MG, Brasil - bethf@ deg.ufla.br

${ }^{2}$ Habilitado em Técnicas Agropecuárias, Professor Doutor em Agronomia (Energia na Agricultura) - Universidade Federal de Lavras/ UFLA - Departamento de Engenharia - Cx. P. 3037 - 37200-000 - Lavras, MG, Brasil - auau@deg.ufla.br

${ }^{3}$ Engenheiro Agrônomo, Professor Mestre em Engenharia Rural - Universidade Federal de Lavras/UFLA - Departamento de Engenharia - Cx. P. 3037 - 37200-000 - Lavras, MG, Brasil - aoliveira@ deg.ufla.br

${ }^{4}$ Engenheiro Agrônomo, Professor Mestre em Solos e Nutrição de Plantas - Universidade Federal de Lavras/UFLA - Departamento de Engenharia - Cx. P. 3037 - 37200-000 - Lavras, MG, Brasil - rvmac@ deg.ufla.br
} 
2006). Para elaborar estudos de análise temporal de uso e cobertura da terra, as fotografias aéreas são fundamentais, principalmente para períodos anteriores ao uso corrente das imagens de satélites.

Furtini (2005) utilizou fotografias aéreas para fazer uma análise temporal da sub-bacia do córrego Centenário em Lavras, MG, em três épocas distintas: 1971, 1986 e 1999. As áreas das classes de uso da terra (área construída, solo exposto, vegetação arbórea e voçoroca) foram comparadas, concluindo que, apesar de ter havido um grande aumento da área construída (a sub-bacia é urbana), a vegetação arbórea permaneceu, ocupando área em torno de $5 \%$ nos três anos estudados.

Rodrigues et al. (2009) utilizaram fotografias aéreas de 1983 e de 2000, para avaliar a evolução do uso e ocupação do solo da sub-bacia do Córrego da Fazenda Glória, Taquaritinga, SP. Os autores concluíram que a classe de cana-de-açúcar tornou-se predominante em 2000, em detrimento de pomares e outras culturas. Observou-se também o aumento das áreas de represas, de fragmentos florestais e de várzeas.

Em alguns levantamentos de uso da terra as imagens de média resolução, obtidas pelos sensores a bordo dos satélites LANDSAT e CBERS, são utilizadas. Altmann et al. (2009) realizaram análise temporal no município de Teutuônia, RS, a partir de imagens do sensor MSS do satélite LANDSAT-2 para o ano de 1976 e imagens do sensor TM do satélite LANDSAT-5 para os anos de 1987, 1997 e 2008. Os resultados apontaram que as áreas florestais cresceram e as áreas de uso agropecuário diminuíram no município.

Análises temporais, utilizando imagens de alta resolução, obtidas pelos sensores dos satélites IKONOS, QUICKBIRD e WORLDVIEW são pouco comuns, principalmente em decorrência do custo de aquisição dessas imagens. Além disso, as técnicas utilizadas para processamento dessas imagens são mais complexas, quando comparadas às imagens de média resolução. No entanto, para a obtenção de mapas com maior detalhamento espacial, estas são ideais.

O campus da Universidade Federal de Lavras (UFLA), com uma área de 476 ha foi fotografado nos levantamentos aerofotogramétricos dos anos de 1964, 1971, 1979 e 1985 . No entanto, até a presente data, ainda não havia sido realizado nenhum mapeamento a partir desses produtos. Entre os anos de 1964 e 2009, transcorreram 45 anos e nesse período o número de estudantes passou de 108 para 3.963, respectivamente, acarretando modificações significativas nas feições do campus da UFLA.

Diante do exposto, neste trabalho, objetivou-se identificar, quantificar e analisar as mudanças ocorridas no campus da UFLA, com base numa série de cartas de uso e cobertura da terra, feitas a partir de imagens de 2009 do satélite QUICKBIRD e fotografias aéreas verticais convencionais, anos de 1964, 1971, 1979 e 1985.

\section{MATERIAL E MÉTODOS}

A metodologia utilizada para identificar, quantificar e analisar as mudanças ocorridas no campus da UFLA incluiu: a) ortorretificação da imagem QUICKBIRD e das fotografias aéreas verticais (F.A.V.); b) definição das categorias e classes de uso e cobertura da terra a serem mapeadas, utilizando levantamento de campo; c) elaboração do mapa de uso e cobertura da terra do ano de 2009; c) elaboração dos mapas de uso e cobertura da terra, a partir de F.A.V. dos anos de 1985, 1979, 1971 e 1964; d) quantificação, análise e descrição das mudanças ocorridas entre os anos estudados.

A área de estudo foi o Campus da Universidade Federal de Lavras, localizado na cidade de Lavras, Minas Gerais. O mapa do limite da UFLA foi produzido a partir de um levantamento de campo com um receptor GPS RTK de dupla frequência (L1+L2). Na Figura 1, apresenta-se a Carta Imagem do Satélite QUICKBIRD, fusão espectral Gram-Schimdt, em composição colorida 321/RGB, com o limite do Campus da UFLA.

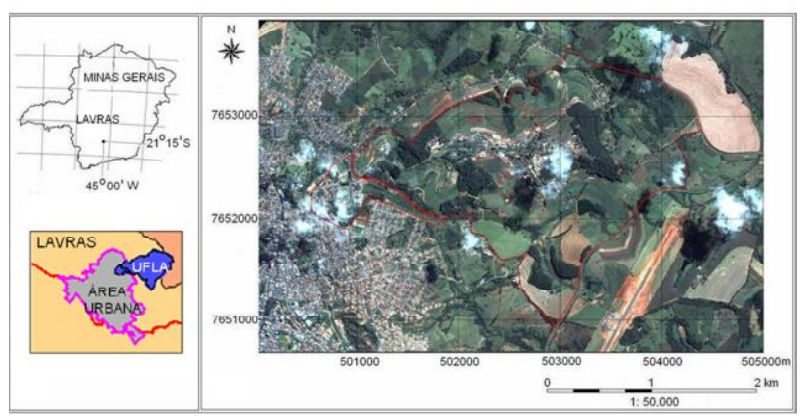

Figura 1 - Carta Imagem do Satélite Quickbird, fusão espectral Gram-Schimdt, em composição colorida 321/RGB, com o limite do Campus da UFLA (linha vermelha). Data: 21/04/2009.

Figure 1 - The QUICKBIRD satellite image, Gram-Schmidt spectral sharpening $321 / R G B$, showing the campus of the Federal University of Lavras with the boundary represented by the red line. Date: 04/21/2009. 
A imagem QUICKBIRD utilizada no trabalho foi gerada em 21/04/2009 às 13h30min com as seguintes características: 01 Banda Pancromática $(0,60 \mathrm{~m}), 04$ Bandas Multiespectrais $(2,4 \mathrm{~m})$, sistema de coordenada UTM, datum WGS 84, ângulo de visada off-nadir $12,9^{\circ}$, formato Geotiff, acompanhadas dos arquivos ISD (Image Support Data) e apresenta $4 \%$ de nuvens.

\subsection{Ortorretificação da imagem QUICKBIRD e das F.A.V.}

A ortofoto é a fotografia que possui ponto de vista no infinito, ou seja, não possui distorção radial (VISUAL INFORMATION SOLUTIONS, 2008).

Para os processos de ortorretificação da imagem QUICKBIRD e das F.A.V. foi gerado um modelo digital de elevação (MDE) e coletados 29 pontos de controle no terreno (PCs) com GPS RTK, contendo coordenadas de latitude, longitude e altitude. Os PCs foram distribuídos por toda a área de abrangência da imagem.

O MDE foi obtido a partir de uma carta planialtimétrica com equidistância entre curvas de nível de 5 metros (escala 1:10.000 m) e de uma carta topográfica do IBGE, folha SF-23-X-C-I-1, com equidistância entre curvas de nível de 20 metros (escala 1:50.000).

Na Tabela 1, estão descritas as características do voo, o ano de obtenção, as faixas do vôo, o número das aerofotos e dos fotoíndices utilizados neste estudo.

O procedimento de ortorretificação das F.A.V. de 1964 incluiu a construção da orientação interna e externa da aerofoto, para gerar a ortofototografia (VISUAL INFORMATION SOLUTIONS, 2008).

O procedimento de ortorretificação não foi realizado para as F.A.V. dos anos de 1971 e 1979, uma vez que não foi possível obter os certificados de calibração das câmaras utilizadas nesses aerolevantamentos. Dessa forma, as fotografias desses dois anos foram corrigidas geometricamente e registradas, utilizando-se pontos de controle da imagem QUICKBIRD ortorretificada. As ortofotografias de 1985, em escala 1:10.000, foram obtidas do acervo das Centrais Elétricas de Minas Gerais (CEMIG).

\subsection{Definições e mapeamento das classes de uso e cobertura da terra}

A definição prévia das categorias e das classes de uso e cobertura da terra foi baseada na nomenclatura proposta por Anderson et al. (1976) e IBGE (2006). Para estabelecimento das classes de uso e cobertura da terra foram feitos levantamentos de campo para identificação e reconhecimento das classes existentes no campo e associação com os padrões das feições registrados na imagem do ano de 2009. Após algumas visitas a campo, observou-se que algumas classes existentes, tais como brejo, área ajardinada e mato não constavam nos manuais de Anderson et al. (1976) e IBGE (2006). Dessa forma, essas classes foram nomeadas conforme o significado dessas palavras, definidas no Dicionário da Língua Portuguesa (HOUAISS, 2002).

As classes existentes no ano de 2009 foram distribuídas em cinco categorias: áreas urbanizadas, áreas agrícolas, áreas de vegetação natural, água e outros usos.

As áreas urbanizadas: compreendem as classes que estão caracterizadas por estruturas como pavimentos, estradas, canteiros e prédios, entre outros. Nessa categoria foram incluídas as vias principais, as áreas construídas, as áreas pavimentadas e as áreas ajardinadas.

As áreas agrícolas compreendem as classes em que estão caracterizadas as explorações agrícolas. Nessa categoria, foram classificadas as culturas temporárias, as pastagens, os cafezais, o pomar e os plantios de eucalipto, candeia e pinus.

As áreas de vegetação natural compreendem as classes em que estão caracterizadas as áreas com cobertura natural, sendo incluídas nessa categoria as áreas caracterizadas como floresta, mata ciliar, cerrado, capoeira e mato.

Tabela 1 - Características das fotografias: realização do voo, ano, faixas de vôo, números das aerofotos, nomenclatura do fotoíndice e escala.

Table 1 - Parameters of the photo: flight, years, flight lines, number of aerial photographs, aero-photo index and scale.

\begin{tabular}{lccccc}
\hline Vôo & Ano & Faixas & Números das fotos & Fotoíndice & Escala \\
\hline USAF & 1964 & $75 \mathrm{~A}$ & $5042-5043$ & 5399 & $1: 60.000$ \\
IBC/GERCA & 1971 & $37 \mathrm{C}$ & $4531-4532-4533$ & SF-23_X-C-I & $1: 25.000$ \\
IBC/GERCA & 1979 & $36 \mathrm{~J}$ & $154249-154250$ & SF-23_X-C-I & $1: 25.000$ \\
IBC/GERCA & 1979 & $36 \mathrm{I}$ & $168002-168003$ & SF-23_X-C-I & $1: 25.000$ \\
CEMIG & 1985 & $2106 \mathrm{D}$ & $125-126-127$ & SF-23_X-C-I & $1: 10.000$ \\
\hline
\end{tabular}


A água inclui córregos (perenes e temporários) e reservatórios artificiais (represas) construídos para abastecimento, uso institucional e irrigação.

Na categoria outros usos foram incluídos outras áreas significativas existentes no campus da UFLA, tais como: campo de futebol, brejo, piscicultura e solo exposto.

A técnica utilizada para interpretar a imagem e as fotografias foi visual, baseando-se nos critérios da fotointerpretação. O primeiro mapa construído foi do ano de 2009, porque o ano mais recente é o único em que se pode observar e confirmar a verdade de campo. Os polígonos referentes às classes de uso e cobertura da terra foram digitalizados manualmente e identificados de acordo com a classe de uso e cobertura. A legenda das classes de uso seguiu os padrões de cores apresentadas pelo IBGE (2006).

O mapa do ano de 1985 foi construído sobrepondose o mapa vetorial do ano de 2009 sobre a ortofotografia do ano de 1985. A seguir, linhas foram incluídas ou excluídas e/ou e polígonos, de acordo com a interpretação das classes na ortofografia de 1985. Os mapas referentes aos anos de 1979, 1971 e 1964 foram construídos da mesma forma, ou seja, sobrepondo-se os mapas vetoriais de 1985, 1979 e 1971 às ortofotografias de 1979, 1971 e 1964, respectivamente.

Para quantificar e analisar as mudanças foram feitas diferenças entre os mapas de duas épocas subsequentes. Os aplicativos utilizados para elaboração do trabalho foram oENVI (VISUALINFORMATION SOLUTIONS, 2008) e o SPRING (CÂMARA et al., 1996).

\section{RESULTADOS E DISCUSSÃO}

A área do campus da UFLA totalizou 476 ha. $\mathrm{Na}$ Tabela 2, estão apresentadas as áreas das classes e categorias de uso e cobertura da terra, (em ha), para todos os anos estudados.

Na Figura 2, apresenta-se a legenda de cores relativa às classes de uso da terra. Essa legenda deve ser utilizada para interpretar as "Cartas de Uso e Cobertura do Campus da UFLA”, para os anos de 2009, 1985, 1979, 1971 e 1964, apresentadas na Figura 3. Com auxílio da Tabela 2 e da Figura 3 podem ser feitas análises das diferenças (mudanças), entre as classes e categorias de uso e cobertura da terra, ocorridas no campus, entre os anos estudados. Essas análises seguem a ordem inversa de construção dos mapas, partindo-se da informação mais antiga, de 1964, para a mais recente, 2009.

Áreas Urbanizadas: em 1964 e 2009 havia, respectivamente, 6,2 e 65,79 ha dessa categoria, conforme pode ser visto na Tabela 2. Esse aumento ocorreu, principalmente em função da demanda por área construída para atender a mais pessoas no campus.

Em 1964, o campus novo não tinha sido construído, pois essa área, em processo de desapropriação, não pertencia a UFLA ainda. O campus novo foi construído entre 1964 e 1971, passando a categoria "área urbanizada" de 6,24 ha para 24,4 ha, nesse período.

Uma mudança significativa nessa categoria ocorreu entre 1971 (24,4 ha) e 1979 (40,07 ha). Observando as cartas de uso referentes a esses dois anos (Figura 3), percebe-se que essa mudança esteve relacionada ao aumento da área construída e da área ajardinada que passaram, respectivamente de 5 ha para 9,06 ha e de 12,48 ha para 22,18 ha entre 1971 e 1979.

Entre os anos de 1979 e 1985 a mudança na categoria “área urbanizada" ocorreu, principalmente, em razão do aumento da área ajardinada. Na Figura 3, em 1979, pode ser visto que as "culturas temporárias" (cor amarela) faziam limite com a parte sul do eixo da avenida central e que em 1985, essa classe foi transformada em área ajardinada (verde claro), passando para a categoria "áreas urbanizadas".

Outra alteração expressiva da categoria "áreas urbanizadas" ocorreu entre os anos de 1985 e 2009. A classe “área construída”, que passou de 9,78 para 25,73 ha foi a que mais contribuiu para esta alteração (Tabela 2). Nesse período o número de estudantes passou de 1.575 para 3.963 . Na Figura 3, ano de 2009, pode ser visualizada a extensão da categoria "áreas urbanizadas" neste ano, cobrindo uma área de 65,79 ha (Tabela 2).

Áreas de Vegetação Natural: de um modo geral, pode ser visto na Tabela 2 que essa categoria teve uma redução do ano de 1964 (45,95 ha) para o ano de 1971 (38,08 ha) e que, a partir deste ano, essa foi aumentando progressivamente. A classe "floresta" foi a que sofreu maior redução (11,35 ha), do ano de 1964 (28,43 ha), para o ano de 1971 (17,08 ha). Em 1964, haviam 1,75 ha de mata ciliar no campus, sendo que em 1971 a sua área era insignificante ( 0,14 ha), ou seja, houve corte de mata ciliar. No ano de 1964, não se observou a classe cerrado, que no ano de 1971 totalizou 4,73 ha. Isso indica que o cerrado existente em 2009 é um cerrado regenerado após o ano de 1964, ou seja, é relativamente recente, com cerca de 40 anos de existência.

Como em 1971 quase não havia mata ciliar e houve aumento desta classe com o passar dos anos, concluiu-se que as existentes atualmente foram regeneradas a partir deste ano. A classe floresta aumentou 23,17 ha de 1971 (17,08 ha) para 1979 (40,25 ha).

Cerne, Lavras, v. 19, n. 1, p. 35-42, jan./mar. 2013 
Tabela 2 - Áreas das classes e categorias de uso e cobertura da terra (ha), para os anos de 2009, 1985, 1979, 1971 e 1964.

Table 2 - Areas of classes and categories of land use and land cover (ha) for the years 2009, 1985, 1979, 1971 and 1964.

\begin{tabular}{|c|c|c|c|c|c|}
\hline \multirow{2}{*}{$\begin{array}{l}\text { Classes de Uso e } \\
\text { Cobertura da terra }\end{array}$} & \multicolumn{5}{|c|}{ Anos } \\
\hline & 2009 & 1985 & 1979 & 1971 & 1964 \\
\hline \multicolumn{6}{|l|}{ Áreas Urbanizadas } \\
\hline Vias principais & 8,80 & 6,95 & 7,13 & 6,62 & 1,63 \\
\hline Área pavimentada & 3,94 & 1,76 & 1,70 & 0,3 & 0,05 \\
\hline Área construída & 25,73 & 9,78 & 9,06 & 5 & 2,95 \\
\hline Área ajardinada & 27,32 & 26,71 & 22,18 & 12,48 & 1,61 \\
\hline Total & 65,79 & 45,2 & 40,07 & 24,4 & 6,2 \\
\hline \multicolumn{6}{|c|}{ Áreas de Vegetação Natural } \\
\hline Mata Ciliar & 12,42 & 5,82 & 4,21 & 0,14 & 1,75 \\
\hline Floresta & 56,38 & 45,9 & 40,25 & 17,08 & 28,43 \\
\hline Cerrado & 3,72 & 4,04 & 2,92 & 4,73 & - \\
\hline Capoeira & 15,24 & 25,59 & 16,91 & 7,43 & 7,32 \\
\hline Mato & 25,42 & 17,37 & 10,96 & 9 & 8,47 \\
\hline Total & 113,18 & 97,91 & 75,25 & 38,08 & 45,95 \\
\hline \multicolumn{6}{|l|}{ Áreas Agrícolas } \\
\hline Pastagem & 154,89 & 114,05 & 122,43 & 192,75 & 260,41 \\
\hline Eucalipto & 21,08 & 10,33 & 5,72 & - & 12,8 \\
\hline Pinus & 8,50 & 1,05 & 1,05 & - & - \\
\hline Cultura temporária & 56,85 & 144,07 & 136,34 & 121,73 & 64,91 \\
\hline Café & 17,16 & 9,08 & 32,32 & 18,65 & 14,84 \\
\hline Pomar & 12,13 & 19,74 & 21,94 & 20,21 & 16,96 \\
\hline Café sombreado & - & - & 8,06 & 3,22 & 14,27 \\
\hline Total & 270,61 & 298,32 & 327,86 & 356,56 & 384,26 \\
\hline Água & 7,94 & 6,59 & 4,64 & 1,68 & 0,3 \\
\hline \multicolumn{6}{|l|}{ Outros Usos } \\
\hline Brejo & 9,73 & 17,01 & 18,04 & 21,96 & 16,22 \\
\hline Piscicultura & 0,55 & 1,08 & 1,08 & - & - \\
\hline Campo de futebol & 2,56 & 2,18 & 2,18 & 0,53 & 0,53 \\
\hline Solo exposto & 4,81 & 7,20 & 6,77 & 7,72 & 2,08 \\
\hline Floresta rala & - & - & - & 24,63 & 19,59 \\
\hline Total & 17,86 & 27,56 & 28,07 & 54,84 & 39,29 \\
\hline
\end{tabular}

O aumento das áreas de vegetação natural a partir do ano de 1979, talvez seja explicado pela regeneração dessas classes. No ano de 2009, o campus possuía 113,18 ha de áreas de vegetação natural (floresta, mata ciliar, cerrado, capoeira e mato), sendo este o maior valor encontrado em todas as épocas estudadas.
As matas ciliares também estavam mais recuperadas em 2009, apresentando 12,42 ha, conforme pode ser observado na Tabela 2. As áreas de capoeira sofreram redução do ano de 1985 (25,59 ha), para o ano de 2009 (15,24 ha), ou seja, essas áreas foram regeneradas e passaram a pertencer à classe "floresta".

Cerne, Lavras, v. 19, n. 1, p. 35-42, jan./mar. 2013 


\begin{tabular}{|llll|}
\hline LEGENDA & Eucalipto & AREAS DE VEGETAÇAO NATURAL & OUTROS USOS \\
AREAS URBANIZADAS & Candeia & Mata ciliar & Brejo \\
Vias principais & Pastagem & Floresta & Piscicultura \\
Area pavimentada & Cultura temporária & Cerrado & Campo de futebol \\
Area construida & Café & Capoeira & Solo exposto \\
Area ajardinada & Pomar & Mato & Café sombreado (1964) \\
AREAS AGRICOLAS & AGUA & & Floresta rala (1971) \\
Pinus & Agua & & Setor de suinos (1964) \\
\hline
\end{tabular}

Figura 2 - Legenda das classes de uso e cobertura da terra.

Figure 2 - Land use and land cover classes legend.

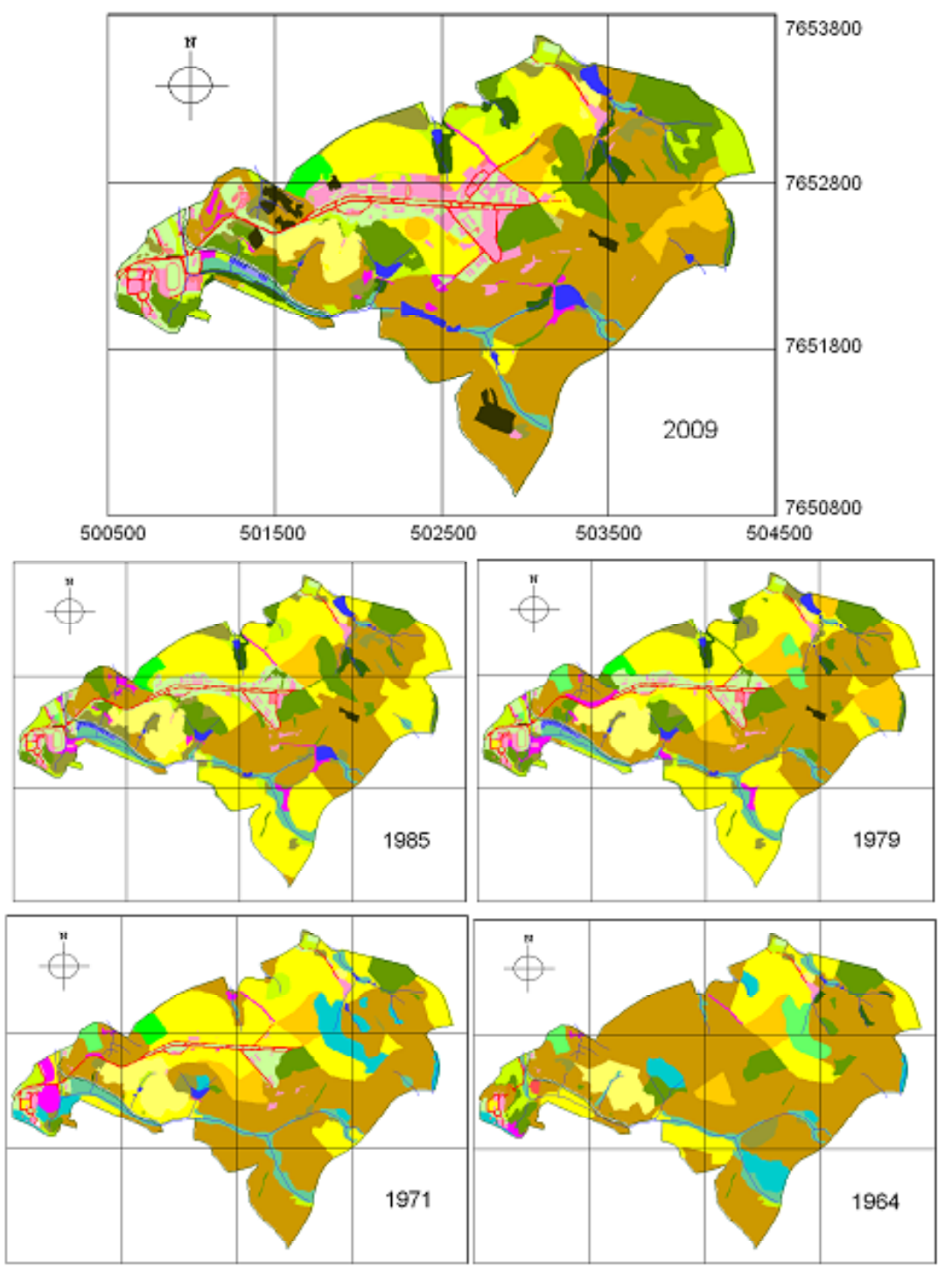

Figura 3 - Cartas de Uso e Cobertura do Campus da UFLA para os anos de 2009, 1985, 1979, 1971 e 1964.

Figure 3 - Land use and land cover maps of the UFLA campus for the years 2009, 1985, 1979, 1971 and 1964.

Cerne, Lavras, v. 19, n. 1, p. 35-42, jan./mar. 2013 
Das áreas de florestas existentes atualmente, apenas dois remanescentes possuem, com certeza, mais de 40 anos, pois já existiam em 1964.

Áreas Agrícolas: a maior parte do campus já foi utilizada para atividades agrícolas, porém houve redução desse tipo de uso, do ano de 1964 (384,19 ha), para o ano de 2009 (271,16 ha), conforme Tabela 2.

Na Figura 3, em 1964, pode ser observada que a maior parte do campus que era utilizada com pastagem (260,41 ha) sofreu redução de 67,26 ha para o ano de 1971 (192,75 ha). Em 1964, havia menos áreas cultivadas com café $(14,84$ ha) e mais com café sombreado $(14,27$ ha) do que em 1971 (Tabela 2). Em 1964, foram encontradas áreas com reflorestamentos de eucalipto, que corresponderam a 12,8 ha. Em 1971, não foram encontradas áreas com reflorestamentos de pinus e eucalipto no campus.

Na Figura 3, 1971, pode ser observado que grande parte do campus era utilizada com pastagem. Houve redução de 70,32 ha de pastagem do ano de 1971 (192,75 ha), para o ano de 1979 (122,43 ha). Havia menos áreas cultivadas com café (18,65 ha) e café sombreado ( 3,22 ha) em 1971 do que em 1979 (Tabela 2).

$\mathrm{Na}$ Tabela 2, pode ser visto que 327,87 ha era destinado à área agrícola, em 1979 e 298,32 ha em 1985. Dentro dessa categoria, pode ser observado, que as áreas de eucalipto e café foram as que sofreram as mudanças mais significativas. No ano de 1979, havia 5,72 ha de reflorestamento com eucalipto e, em 1985, essa classe apresentou 10,33 ha, havendo aumento de 4,61 ha. As áreas cultivadas com café correspondiam a 32,32 ha em 1979 e, em 1985, foram de 9,08 ha, havendo redução de 23,24 ha. Além das áreas cultivadas com café, no ano de 1979, observaram-se ainda áreas cultivadas com café sombreados, que corresponderam a 8,06 ha.

$\mathrm{Na}$ Tabela 2, pode ser observado que as áreas de eucalipto e pinus aumentaram significativamente do ano de1985 para 2009. Na Figura 3 (1985), pode ser observado que as áreas destinadas a culturas temporárias (cor amarela) eram muito expressivas, em 1985 (144,07 ha) e em 2009 correspondem a 56,85 ha, tendo havido redução de 87,22 ha. As mudanças ocorridas se referem, principalmente, à utilização dessas áreas com reflorestamentos, café e pastagem, que sofreram aumento.

Água: no ano de 1964 não havia represas no campus, conforme Figura 3. A primeira represa construída no campus foi a Represa São Miguel, que aparece pela primeira vez em 1971.

O aumento dessa classe do ano de 1971, para o ano de 1979, se refere à construção da Represa da EPAMIG, cujo centro está situado nas coordenadas UTM $503.438 \mathrm{~m}$ Ee 7.853.425 m N, conforme representada na Figura 3, ano de 1979.

Do ano de 1979 (4,64 ha), para o ano de 1985 (6,59 ha), o aumento da classe "água" ocorreu em função da construção da "Represa da Zootecnia", cujo centro está situado nas coordenadas UTM $503.282 \mathrm{~m} \mathrm{E} \mathrm{e} 7.652 .113 \mathrm{~m}$ N, Figura 3, ano de 1985.

Entre os anos de 1985 e 2009, ocorreu a construção da Represa Encantada (1,4 ha), conforme pode ser observado, comparando-se as Figura 3, anos 1985 e 2009.

Outros usos: essa categoria é a menos expressiva em todos os anos estudados e na última interpretação, em 2009 , totalizou apenas $17,86 \mathrm{ha}$, representada pelas classes brejo, piscicultura, campo de futebol e solo exposto.

A classe brejo sofreu diminuição ao longo dos anos, sendo essas áreas transformadas em represas; a piscicultura foi construída após 1971, porém teve sua área reduzida a partir de 1985, em razão da diminuição na disponibilidade de água para esse tipo de uso. O estádio de futebol, cujo centro está situado nas coordenadas UTM $500.890 \mathrm{~m} \mathrm{E} \mathrm{e}$ 7.652.237 m N, foi construído após1971, uma vez que só aparece na F.A.V. do ano de 1979. As áreas de solo exposto em 2009 corresponderam a 4,81 ha da área total do campus, sendo constituídas por fragmentos em diferentes estágios de degradação.

De modo geral, observou-se que da primeira F.A.V. disponível, do ano de 1964, até a imagem de 2009 do satélite Quickbird, o campus da Universidade apresentou dinâmica de uso e cobertura coerente com as épocas e com o contexto de crescimento que o país experimentou na mesma época. Assim, as variações entre classes, como redução de área plantada e aumento de área construída, por exemplo, estão relacionadas ao crescimento da universidade no período. Resultados semelhantes (ALTMANN et al., 2009; FURTINI, 2005; RODRIGUES et al., 2009), com as necessárias adequações para as situações específicas, uma vez que as análises não foram feitas para exatamente o campus de uma universidade nem para as mesmas classes, também estão ligados a um contexto mais amplo, ou seja, o das prioridades políticas, econômicas, sociais e ambientais e estão relacionados à situação e ao desenvolvimento local, regional e do país nos períodos analisados.

Cerne, Lavras, v. 19, n. 1, p. 35-42, jan./mar. 2013 
Em razão da importância da história da UFLA, parte deste trabalho foi publicada no jornal da Universidade Federal de Lavras com o título "Em harmonia com a natureza". Na reportagem estão disponibilizadas a fotografia do campus da UFLA do ano de 1964 e a imagem do satélite Quickbird de 2009, no seguinte endereço:

http://www.ascom.ufla.br/noticia_detail.php?id=2493

\section{AGRADECIMENTOS}

À Fundação de Amparo à Pesquisa do Estado de Minas Gerais (FAPEMIG), processoSHA-APQ-2925-3-12/07.

\section{REFERÊNCIAS}

ALTMANN, A. L.; ECKHARDT, R. R.; REMPEL, C. Evolução temporal do uso e cobertura da terra: estudo de caso no município de Teutônia, RS, Brasil. Revista Brasileira de Cartografia, Rio de Janeiro, v. 61, n. 3, p. 273-283, 2009.

ANDERSON, J. R.; HARDY, E. E.; JOHN, T. R.; WITMER, R. E. A land use and land cover classification system for use with remote sensor data. Washington: U.S. Government Printing Office, 1976. 36 p.

CÂMARA, G.; SOUZA, R. C. M.; FREITAS, U. M.;

GARRIDO, J. Spring: integrating remote sensing and GIS by object-oriented data modelling. Computers \& Graphics,

London, v. 20, n. 3, p. 395-403, 1996.

FURTINI, M. B. Análise temporal da Sub-bacia do

Córrego Centenário em Lavras, MG. 2005. 96 p.

Dissertação (Mestrado em Engenharia Agrícola) - Universidade Federal de Lavras, Lavras, 2005.

HOUAISS, A. Dicionário Houaiss da língua portuguesa. Rio de Janeiro: Objetiva, 2001. 2922 p.

INSTITUTO BRASILEIRO DE GEOGRAFIA E ESTATÍSTICA. Manual técnico de uso da terra. 2. ed. Rio de Janeiro, 2006. 91 p.

LILLESAND, T. M.; KIEFER, R. W.; CHIPMAN, J. W. Introduction to visual interpretation. In: Remote sensing and image interpretation. New York: J. Wiley, 2008. p. 189-324.

RODRIGUES, F. M.; PISSARRA, T. C. T.; CAMPOS, S. Análise temporal do uso e ocupação do solo na microbacia hidrográfica do Córrego da Fazenda Glória, município de Taquaritinga, SP. Irriga, Botucatu, v. 14, n. 3, p. 314-324, 2009.

VISUAL INFORMATION SOLUTIONS. ENVI - Environment for Visualizing Images. Version 4.6.1. Boulder, 2008. 